\title{
Hidrólise enzimática de fibras de cotilédones de soja e caracterização das frações sólidas e solúveis
}

\author{
Neusa Fátima Seibel(1) e Adelaide Del Pino Beléia(2) \\ (1)Universidade Tecnológica Federal do Paraná, Estrada dos Pioneiros, no 3.131, CEP 86000-000 Londrina, PR. E-mail: neusaseibel@utfpr.edu.br \\ (2)Universidade Estadual de Londrina, Departamento de Ciência e Tecnologia de Alimentos, Caixa Postal 6001, CEP 86051-970 Londrina, PR. \\ E-mail: beleia@uel.br
}

\begin{abstract}
Resumo - O objetivo deste trabalho foi determinar as melhores condições de hidrólise enzimática de fibras alimentares de cotilédones de soja, original (FAO) e micronizada (FAM), e caracterizar os hidrolisados sólidos e solúveis. As amostras foram hidrolisadas com carboidrase $\left(200 \mu \mathrm{L} \mathrm{g}^{-1}\right.$, durante 12 horas, a $\left.30^{\circ} \mathrm{C}\right)$ ou com protease $\left(150 \mu \mathrm{L} \mathrm{g} \mathrm{g}^{-1}\right.$, durante 5 horas, a $\left.55^{\circ} \mathrm{C}\right)$. A fração sólida das amostras tratadas com carboidrase teve redução de $73 \%$ dos carboidratos e de $50 \%$ dos ácidos urônicos iniciais; houve aumento da concentração de proteínas e aumento da solubilidade e volume de intumescimento comparado com o material não hidrolisado. Proteínas de reserva da soja - beta-conglicinina e glicinina - foram extraídas das fibras alimentares não hidrolisadas e identificadas por eletroforese. A protease solubilizou $54 \%$ do total de proteínas das amostras e formou peptídeos com peso molecular menor que $10 \mathrm{KDa}$ e uma banda de peso molecular próximo aos $25 \mathrm{KDa}$, provavelmente glicoproteína de parede celular, e deixou uma fração sólida com $76 \%$ de fibras alimentares totais. A microscopia eletrônica de varredura mostrou alterações físicas para a FAO hidrolisada com protease, com superfície mais porosa do que a FAM. O tratamento enzimático foi efetivo em alterar a composição química e estrutural das fibras, dando novas perspectivas para aplicações tecnológicas.
\end{abstract}

Termos para indexação: Glycine max, carboidrase, eletroforese, fibra alimentar, protease.

\section{Enzymatic hydrolyses of fibers from soy cotyledons and characterization of solid and soluble fractions}

\begin{abstract}
The objective of this work was to determine the best enzymatic hydrolysis conditions for dietary fiber from soybean cotyledons, original (ODF) and milled (MDF), and to characterize the solid and soluble hydrolytes. The samples were hydrolyzed with carbohydrase $\left(200 \mu \mathrm{L} \mathrm{g}^{-1}\right.$ for 12 hours, at $\left.30^{\circ} \mathrm{C}\right)$ or protease $\left(150 \mu \mathrm{L} \mathrm{g}^{-1}\right.$ for 5 hours, at $\left.55^{\circ} \mathrm{C}\right)$. The solid fraction of the samples treated with carbohydrase had a reduction of $73 \%$ for the carbohydrates and of $50 \%$ for the uronic acids of the initial material; there was an increase in protein concentration and in solubility and swelling volume in comparison to the nonhydrolyzed material. Soybean storage proteins - beta-conglycinin and glycinin - were extracted from nonhydrolyzed dietary fiber and identified by electrophoresis. Protease solubilized $54 \%$ of the sample's total protein content, formed peptides with molecular weight lower than $10 \mathrm{KDa}$, a band with molecular weight of $25 \mathrm{KDa}$ probably cell-wall glycoprotein, and left a solid fraction with $76 \%$ total dietary fiber. Scanning electron microscopy showed physical alterations for ODF hydrolyzed with protease, with more superficial pores than MDF. The enzymatic treatment was effective in altering the chemical and structural composition of the fibers, resulting in new perspectives for technological applications.
\end{abstract}

Index terms: Glycine max, carbohydrase, electrophoresis, dietary fiber, protease.

\section{Introdução}

A fibra dos cotilédones de soja é a fração insolúvel obtida após o processamento do isolado proteico, constituída principalmente de polissacarídeos de parede celular, mas ainda com aproximadamente $26 \%$ de proteínas. As fibras alimentares, em geral, são definidas como macromoléculas resistentes à digestão pelas enzimas do trato gastrointestinal humano, e são essencialmente compostas de componentes da parede celular, tais como polissacarídeos e lignina. A quantidade recomendada de consumo diário para que ocorram efeitos benéficos à fisiologia humana é entre 25 e $30 \mathrm{~g}$ de fibras alimentares totais, sendo $75 \%$ composta de fibras insolúveis. A principal propriedade funcional das fibras vegetais é a hidratação, possivelmente pela presença de componentes insolúveis, como celulose, hemicelulose e lignina, mas que são materiais higroscópicos (Auffret et al., 1994; López et al., 1996; Tharanathan \& Mahadevamma,

Pesq. agropec. bras., Brasília, v.44, n.10, p.1336-1345, out. 2009 
2003). Os processos tecnológicos aos quais as fontes de fibras são submetidas, como moagem, secagem, aquecimento e extrusão, modificam as propriedades físicas da matriz vegetal, e afetam as propriedades de hidratação (Guillon \& Champ, 2000).

A incorporação de fibras em alimentos pode causar modificações indesejáveis particularmente quanto ao sabor e à textura. As fibras vegetais têm recebido tratamentos para alterar algumas características da complexa estrutura física dos compostos da parede celular, para facilitar a incorporação em alimentos (Marsman et al., 1997; Tharanathan \& Mahadevamma, 2003). Modificações intencionais podem ser por tratamentos químicos, mecânicos, enzimáticos ou térmicos, com objetivos de aumentar a funcionalidade e a disponibilidade de nutrientes, produzir hidrolisados com peptídeos definidos, isolar peptídeos fisiologicamente ativos e remover sabores, odores e compostos tóxicos (Lahl \& Braun, 1994).

A hidrólise enzimática é preferida para aplicação em produtos alimentícios, porque pode ser controlada e definida, dependendo do interesse.

Após a hidrólise dos polissacarídeos de parede celular, a concentração de fibras solúveis e o volume de intumescimento das fibras insolúveis aumentam, provavelmente pelo aumento da porosidade, pois o intumescimento depende do tamanho e da distribuição dos poros (Guillon \& Champ, 2000). Há aumento da digestibilidade dos componentes da parede celular se houver aumento de compostos solúveis (Karr-Lilienthal et al., 2005). Nas proteínas, o efeito da hidrólise é percebido principalmente nas propriedades funcionais, como aumento da solubilidade, da capacidade emulsificante e espumante, além de melhorar a disponibilidade dos aminoácidos (Fischer et al., 2001; Tsumura et al., 2005).

O objetivo deste trabalho foi determinar as melhores condições de hidrólise enzimática de fibras de cotilédones de soja e caracterizar os hidrolisados sólidos e solúveis.

\section{Material e Métodos}

Foram utilizadas fibra alimentar original (FAO) e fibra alimentar micronizada (FAM), fornecidas pela empresa Solae Company (Esteio, RS). A FAO continha $28,2 \%$ de proteína e $59,4 \%$ de fibra alimentar total e a FAM continha $27,6 \%$ de proteínas e $62,5 \%$ de fibra alimentar total.

Para determinar as melhores condições de hidrólise enzimática de carboidratos e proteínas das fibras de soja, foram usados dois tratamentos em esquema fatorial $2^{3}$ mais dois pontos centrais para cada um deles, no total de dez experimentos para cada enzima, realizados aleatoriamente com duas repetições. No primeiro tratamento, as variáveis avaliadas foram: concentração de enzima carboidrase de Aspergillus aculeatus, nome comercial Viscozyme L (Novozyme), atividade de 100 unidades $\mathrm{mL}^{-1}(100 \mu \mathrm{L}, 150 \mu \mathrm{Le} 200 \mu \mathrm{L}$ por grama de amostra), tempo de hidrólise (20,30 e $40 \mathrm{~min})$ e temperatura $\left(30,40\right.$ e $\left.50^{\circ} \mathrm{C}\right)$. No segundo tratamento, as variáveis avaliadas foram: concentração de enzima protease de Bacillus liqueniformis P3910 (Sigma) E.C. 3.4.21.14 $(50 \mu \mathrm{L}, 100 \mu \mathrm{L}$ e $150 \mu \mathrm{L}$ por grama de amostra), tempo de hidrólise (20,30 e $40 \mathrm{~min})$ e temperatura $\left(55,60\right.$ e $\left.65^{\circ} \mathrm{C}\right) . \mathrm{O} \mathrm{pH}$ da solução (água) foi fixado em $5,5 \pm 0,1$, para hidrólise dos carboidratos, e em 7,5 $\pm 0,1$, para a hidrólise das proteínas, e ajustado com $\mathrm{NaOH} 5 \%$ e $\mathrm{HCl} 10 \%$. As hidrólises foram realizadas com agitação em banho-maria (Dubnoff T-053, Tecnal, Brasil). As hidrólises dos carboidratos foram analisadas pelos carboidratos solúveis com o método fenol-sulfúrico, segundo Dubois et al. (1956). Os carboidratos foram quantificados por absorção em espectrofotômetro UV-visível Cintra 20 a 490 nm, e a sua concentração foi determinada em curva de calibração de dez pontos, com concentração de 10 a $100 \mu \mathrm{g}$ de glicose e com $\mathrm{R}^{2}=0,9961$. As hidrólises das proteínas foram determinadas pelas proteínas solúveis segundo Lowry et al. (1951). As proteínas foram quantificadas por absorção em espectrofotômetro UV-visível Cintra 20 a 660 nm, e a sua concentração foi determinada em curva de calibração de dez pontos, em concentração de 40 a $400 \mu \mathrm{g}$ de albumina de soro bovino e $\mathrm{R}^{2}=0,9929$.

A determinação das condições das variáveis que mais influenciaram as hidrólises foi realizada com gráficos de superfície de resposta $(200 \mu \mathrm{L}$ de carboidrase por grama de amostra a $30^{\circ} \mathrm{C}$ e $150 \mu \mathrm{L}$ de protease por grama de amostra a $55^{\circ} \mathrm{C}$ ). Nessas condições, novos experimentos (em duplicata) foram realizados para definir o tempo de hidrólise necessário para maximizar a solubilização de carboidratos e proteínas. $\mathrm{O}$ ponto final da hidrólise enzimática foi definido a partir de gráficos entre produto $\mathrm{x}$ tempo, pela verificação do 
menor tempo para se obter a máxima solubilização. As análises foram realizadas de hora em hora, com a primeira análise dos hidrolisados após $30 \mathrm{~min}$ de hidrólise. As frações solúveis foram determinadas de acordo com os métodos descritos anteriormente.

Para conhecer o grau de hidrólise enzimática nas amostras-controle (sem hidrólise), foram determinados os carboidratos solúveis em etanol $80 \%$ e as proteínas solúveis em água, e nas amostras completamente hidrolisadas por ácido sulfúrico $72 \%$ em autoclave durante 1 hora, foram determinados carboidratos $\mathrm{e}$ proteínas totais. Os métodos de fenol sulfúrico e de micro-kjeldahl (usando sulfato de cobre e sulfato de potássio como catalisadores e calculados com fator de correção 6,25 ) foram utilizados, respectivamente.

Após conhecer todas as condições exatas (concentração de enzima, temperatura e tempo de hidrólise) para a maior solubilização de carboidratos e proteínas, foi realizado um novo experimento, em duplicata, para a obtenção e caracterização das frações sólidas e solúveis. Os resíduos sólidos foram secos em uma fina camada sobre lâmina de vidro, em estufa com circulação e renovação de ar TE-394/3 Tecnal, a $30^{\circ} \mathrm{C}$. Os sólidos foram recuperados e triturados em moinho para pequenas amostras IKA A11 basic quimis.

Nos sólidos resultantes da ação da carboidrase, foram avaliados as proteínas totais (micro-kjeldahl) e os pesos moleculares por eletroforese. A funcionalidade tecnológica foi determinada pela solubilidade das proteínas das amostras em diferentes $\mathrm{pH}$, volume de intumescimento (VI), índice de absorção de água (IAA), índice de absorção de óleo (IAO) e atividade emulsificante (AE), conforme descrito por Seibel (2006).

O peso molecular das proteínas foi determinado segundo Marsman et al. (1997) e Maruyama et al. (2003). As proteínas de FAO e FAM e dos hidrolisados foram extraídas em solução tampão Tris- $\mathrm{HCl} 62,5 \mathrm{mmol} \mathrm{L}^{-1}$, $\mathrm{pH} 6,8 ; 2 \%$ de SDS; $1 \%$ de beta-mercaptoetanol e $10 \%$ de glicerol durante 1 hora, sob agitação com barra magnética. Em seguida, foram centrifugadas a $10.000 \mathrm{rpm}$ por $30 \mathrm{~min}, \mathrm{a} 10^{\circ} \mathrm{C}$, e, no sobrenadante, foram quantificadas as proteínas totais por microkjeldahl. A análise por eletroforese foi feita em gel de poliacrilamida (SDS-PAGE), gel separador $12 \%$ e gel concentrador 4\%. Uma alíquota com $2 \mathrm{mg}$ de proteína foi diluída em tampão de amostra e utilizada para a corrida em corrente elétrica de $100 \mathrm{~V}$. As bandas das proteínas foram reveladas e fixadas com solução de metanol $40 \%$, ácido acético $10 \%$ e água $50 \%$, com $0,1 \%$ de corante azul brilhante de Coomassie. $\mathrm{O}$ excesso do corante foi retirado com solução metanol $40 \%$, ácido acético $10 \%$ e água $50 \%$. O padrão utilizado foi o BenchMark Protein Ladder invitrogen, com bandas de 10 a $220 \mathrm{KDa}$.

Nas frações solúveis das hidrólises com a carboidrase, foram determinados carboidratos totais por fenol sulfúrico e ácidos urônicos segundo Kintner \& Van Buren (1982), com uso de uma curva de calibração de seis pontos, em concentração de 10 a $60 \mu \mathrm{g}$ de ácido galacturônico e $\mathrm{R}^{2}=0,9791$.

As frações sólidas das hidrólises com a protease foram avaliadas quanto aos teores de proteínas totais com o método de micro-kjeldahl; e as fibras alimentares solúveis, insolúveis e totais, com o método enzimático-gravimétrico, segundo AOAC no 985.29 (AOAC International, 1995), usando o kit de ensaio de fibra alimentar total da Sigma (TDF 100A) e tampão fosfato $0,08 \mathrm{~mol} \mathrm{~L}^{-1}$ e pH 6. As frações solúveis das hidrólises com a protease foram caracterizadas por eletroforese, segundo Marsman et al. (1997) e Maruyama et al. (2003).

A estrutura física dos hidrolisados sólidos da protease e da carboidrase, assim como das amostras não hidrolisadas, foi avaliada por microscopia eletrônica de varredura. As amostras foram colocadas sobre fita de carbono dupla-face e colada em "stubs", onde foram recobertas com ouro em metalizador Bal-Tec SCD 050 Sputter Coater. Em seguida, foram observadas em microscópio eletrônico de varredura (Quanta 200, FEI Company, Hillsboro, EUA), sob tensão de $20 \mathrm{kv}$. As densidades original e micronizada das fibras de cotilédones foram determinadas diretamente com um cilindro de vidro graduado para medir $9 \mathrm{~mL}$. Este volume foi pesado e a densidade foi calculada pela razão do peso e do volume e expressa em $\mathrm{g} \mathrm{mL}^{-1}$.

Após a realização dos experimentos, foram gerados gráficos de superfície de respostas para conhecer a influência de cada variável na solubilização de carboidratos e proteínas. Os dados foram avaliados por ANOVA e, para comparar a diferença entre as médias, foi utilizado o teste de Tukey, a 5\% de probabilidade. 


\section{Resultados e Discussão}

O aumento na concentração da enzima carboidrase resultou em aumento dos carboidratos solúveis para amostras FAO e FAM (Figura 1). A maior concentração enzimática promoveu o aumento dos carboidratos solúveis de $2,8 \%$ para FAO e $2,2 \%$ para FAM, quando comparada à menor concentração de enzima. $\mathrm{O}$ tempo e a temperatura não afetaram a concentração de carboidratos solúveis.

Nos experimentos com protease, foram obtidas as maiores concentrações de proteínas solúveis de FAO e FAM, com a maior concentração de enzimas (Figura 2). As proteínas solúveis da FAO aumentaram em 10,2\% quando usado maior nível de concentração enzimática, e $8 \%$ com maior tempo de hidrólise. Para FAM, houve interação entre tempo e temperatura no maior nível das variáveis e aumento de $6,8 \%$ em proteínas

A

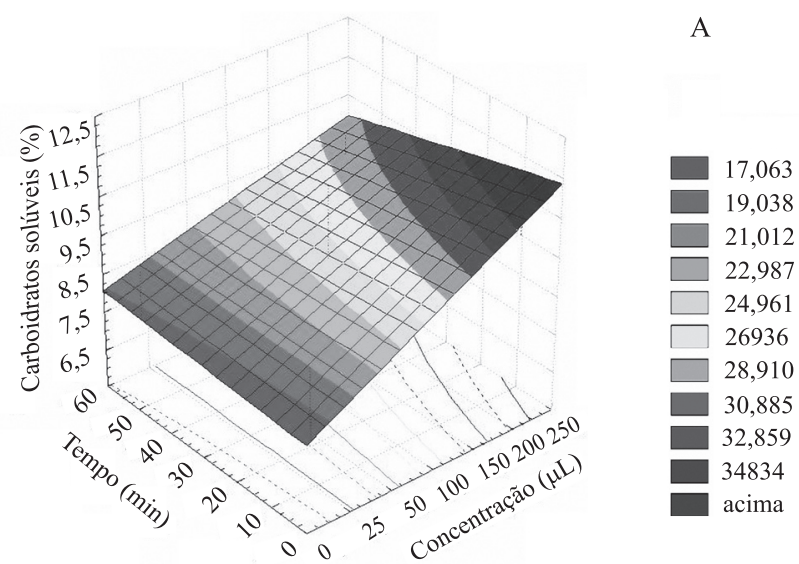

B



Figura 1. Obtenção máxima de carboidratos solúveis das fibras de cotilédones de soja original (A) e micronizada(B). Os valores fora das faixas de tempo (20, 30 e $40 \mathrm{~min})$ e concentração (50, 100 e $150 \mu \mathrm{L}$ ) testadas referem-se a extrapolações geradas pelo programa Statistica. solubilizadas. Houve interação entre concentração de enzima e temperatura de hidrólise, tendo aumentado em $9,5 \%$ as proteínas solúveis quando um dos fatores foi utilizado no nível superior e outro no inferior, mas, quando a concentração de $150 \mu \mathrm{L} \mathrm{g}^{-1}$ foi utilizada, houve aumento de $12 \%$ na concentração de proteínas solúveis.

Foi selecionada a concentração de $200 \mu \mathrm{L} \mathrm{g}^{-1}$ de carboidrase para a hidrólise da FAO e FAM e temperatura de $30^{\circ} \mathrm{C}$ (essa variável não influenciou a solubilidade, economizando-se energia), a fim de determinar o tempo necessário para se obter o máximo de carboidratos solúveis. A quantidade de carboidratos solubilizados foi determinada por período de 13 horas, mas, após 12 horas de hidrólise, a carboidrase hidrolisou $68 \%$ da FAO e $70 \%$ da FAM, e esse tempo foi considerado o menor para obter a maior

A

B

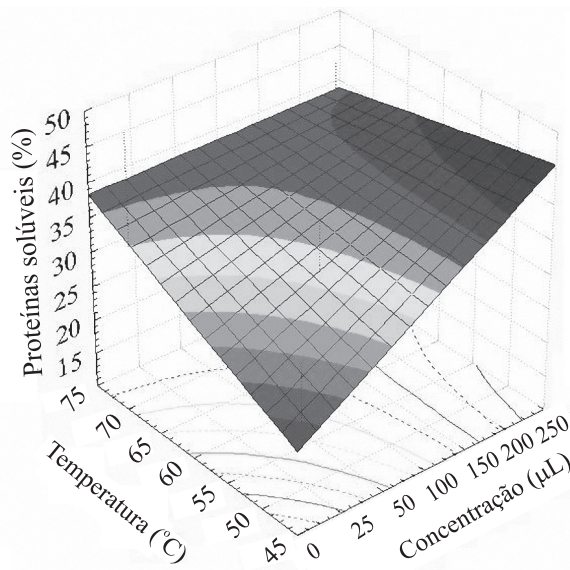

Figura 2. Obtenção máxima de proteínas solúveis das fibras de cotilédones de soja original (A) e micronizada (B). Os valores fora das faixas de tempo (20, 30 e $40 \mathrm{~min})$, concentração $(50,100$ e $150 \mu \mathrm{L})$ e temperatura $\left(55,60\right.$ e $\left.65^{\circ} \mathrm{C}\right)$ testadas referem-se a extrapolações geradas pelo programa Statistica.

Pesq. agropec. bras., Brasília, v.44, n.10, p.1336-1345, out. 2009 
solubilização de carboidratos. A hidrólise enzimática foi comparada aos carboidratos solúveis em amostras de FAO e FAM sem tratamento e amostras totalmente hidrolisadas por hidrólise química (autoclavagem de 1 hora em ácido sulfúrico 72\%). Na FAM, o resultado da hidrólise enzimática foi igual ao da hidrólise química com $70 \%$ do carboidrato inicial hidrolisado (Tabela 1). A hidrólise enzimática na FAO resultou em 7\% menos carboidratos solúveis, em comparação à hidrólise química, provavelmente pelo tamanho das partículas, pois a micronizada tem menor granulometria. A carboidrase de Aspergillus aculeatus foi considerada adequada para solubilizar os carboidratos das fibras de cotilédones de soja, mas não se consegue uma hidrólise completa, em razão da complexidade estrutural dos carboidratos da soja (Fischer et al., 2001).

Para o experimento do tempo de hidrólise, com protease em FAO e FAM, a temperatura selecionada foi baseada nos resultados da FAM, pois esse fator não influenciou a hidrólise da FAO. Assim, foram utilizadas a maior concentração $\left(150 \mu \mathrm{L} \mathrm{g} \mathrm{g}^{-1}\right)$ e a menor temperatura de hidrólise $\left(55^{\circ} \mathrm{C}\right)$, para evitar a desnaturação térmica da protease. As duas amostras foram hidrolisadas por até 10 horas, mas o menor tempo para a máxima solubilização das proteínas das fibras de soja foi definido em 5 horas, quando a quantidade de proteínas solubilizadas das proteínas totais foi $61 \%$ para a FAO e $67 \%$ para a FAM.

Tabela 1. Médias dos carboidratos e proteínas solúveis no controle e após a hidrólise química ${ }^{(1)}$.

\begin{tabular}{lcc}
\hline Tratamentos & FAO & FAM \\
\hline & Carboidratos solúveis $(\%)$ \\
Controle & $4,0 \pm 0,1$ & $8,5 \pm 0,3$ \\
Hidrólise química & $73,9 \pm 2,5$ & $70,0 \pm 0,9$ \\
\hline & \multicolumn{2}{c}{ Proteínas solúveis $(\%)^{(2)}$} \\
Controle & $7,9 \pm 0,6$ & $13,3 \pm 0,4$ \\
Hidrólise química & $28,2 \pm 0,2$ & $27,6 \pm 0,1$ \\
\hline
\end{tabular}

${ }^{(1)}$ Média \pm desvio-padrão das determinações realizadas em triplicata, em base seca. FAO, fibra alimentar original; FAM, fibra alimentar micronizada.

${ }^{(2)}$ Total de proteínas presentes nas amostras, em base seca.
Depois da determinação dos menores tempos para solubilizar os maiores percentuais de carboidratos (12 horas) e proteínas (5 horas), novas hidrólises foram realizadas com todas as condições ideais para a carboidrase e para a protease, para caracterizar as frações sólidas e solúveis.

As frações sólidas da hidrólise com carboidrase tiveram em média $62 \%$ a mais de proteínas do que as amostras antes da hidrólise (Tabela 2). Caso haja interesse em aumentar o rendimento em proteínas por extração, a aplicação da Viscozyme L pode permitir extrair quantidades adicionais de proteínas para serem usadas em produtos alimentícios.

A hidrólise enzimática com carboidrase afetou as propriedades tecnológicas dos materiais sólidos resultantes da hidrólise (Tabela 2). O volume de intumescimento foi maior após a hidrólise, enquanto o índice de absorção de água foi menor, provavelmente em razão das mudanças na estrutura física ocorridas durante a hidrólise, uma vez que esse índice depende da conformação molecular, tamanho das partículas, número de sítios de ligação das moléculas e força de centrifugação; e o volume de intumescimento depende da densidade, porosidade e solubilidade (Chou \& Morr, 1979; Thibault et al., 1992; Auffret et al., 1994). O volume de intumescimento da fração sólida da hidrólise da FAM foi menor que o da FAO, provavelmente devido às diferenças do tamanho das partículas pela micronização. Guillon \& Champ (2000) justificaram o aumento do volume de intumescimento das fibras insolúveis, provavelmente pelo aumento da porosidade, e a menor absorção de água pelo tamanho e distribuição dos poros.

O índice de absorção de óleo não foi influenciado pela hidrólise com carboidrase. A atividade emulsificante das frações sólidas das fibras hidrolisadas foi menor que nas amostras não hidrolisadas, e a capacidade emulsificante não pôde ser verificada porque, durante

Tabela 2. Proteínas e propriedades funcionais da fração sólida, carboidratos totais e ácidos urônicos da fração solúvel das fibras dos cotilédones de soja após a hidrólise com a carboidrase, comparadas com as amostras não hidrolisadas ${ }^{(1)}$.

\begin{tabular}{|c|c|c|c|c|c|c|c|}
\hline \multirow[t]{2}{*}{$\operatorname{Amostras}^{(2)}$} & \multicolumn{5}{|c|}{ Frações sólidas $^{(3)}$} & \multicolumn{2}{|c|}{ Frações solúveis } \\
\hline & Proteínas (\%) & IAA & VI & IAO & $\mathrm{AE}$ & Carboidratos totais (\%) & Ácidos urônicos $\left(\mathrm{mg} \mathrm{g}^{-1}\right)$ \\
\hline FAO não hidrolisada & $28,2 \pm 6,5 b$ & $8,4 \pm 0,2 \mathrm{a}$ & $17,2 \pm 1,0 \mathrm{c}$ & $2,5 \pm 0,1 \mathrm{a}$ & $52,4 \pm 1,4 a$ & $64,6 \pm 0,2 a$ & $17,1 \pm 0,3 \mathrm{a}$ \\
\hline FAO após a hidrólise & $45,5 \pm 1,6 \mathrm{a}$ & $4,1 \pm 0,1 \mathrm{c}$ & $31,0 \pm 0,3 \mathrm{a}$ & $2,4 \pm 0,2 \mathrm{a}$ & $7,9 \pm 1,2 b$ & $47,8 \pm 0,2 b$ & $8,5 \pm 0,1 b$ \\
\hline FAM não hidrolisada & $27,6 \pm 0,1 \mathrm{~b}$ & $5,7 \pm 0,1 \mathrm{~b}$ & $18,0 \pm 0,5 \mathrm{c}$ & $2,4 \pm 0,1 \mathrm{a}$ & $53,0 \pm 0,3 \mathrm{a}$ & $65,2 \pm 0,4 \mathrm{a}$ & $17,1 \pm 0,1 \mathrm{a}$ \\
\hline FAM após a hidrólise & $45,0 \pm 1,2 \mathrm{a}$ & $3,3 \pm 0,1 \mathrm{~d}$ & $21,5 \pm 0,8 b$ & $2,4 \pm 0,2 \mathrm{a}$ & $9,4 \pm 2,0 \mathrm{~b}$ & $46,5 \pm 0,7 \mathrm{~b}$ & $8,1 \pm 0,1 b$ \\
\hline
\end{tabular}

${ }^{(1)}$ Médias \pm desvio-padrão seguidas pela mesma letra, nas colunas, não diferiram pelo teste de Tukey, a 5\% de probabilidade. ${ }^{(2)} \mathrm{FAO}$, fibra alimentar original; FAM, fibra alimentar micronizada. ${ }^{(3)}$ IAA, índice de absorção de água ( $g$ água absorvida por g de amostra); VI, volume de intumescimento (mL de água por g de amostra); IAO, índice de absorção de óleo (g óleo absorvido por g de amostra); AE, atividade emulsificante (\%). Médias de determinações em triplicatas. Proteínas, carboidratos totais e ácidos urônicos, em base seca. 
a determinação, não houve a formação da emulsão. As propriedades emulsificantes são típicas de produtos proteicos e estão relacionadas à solubilidade, mas não basta ter maior quantidade de proteínas com maior solubilidade; é necessário ter aumento na razão hidrofobicidade/hidrofilicidade, pois uma hidrofobicidade relativamente elevada favorece as características emulsificantes das proteínas da soja (Sgarbieri, 1998). Essas características são atribuídas principalmente à combinação de gordura com os grupos não polares das proteínas ou à disponibilidade de grupos lipofílicos (Padilla et al., 1996). Provavelmente, a ação enzimática e a secagem das frações sólidas das fibras alimentares hidrolisadas com carboidrase mudaram a conformação e indisponibilizaram os grupos não polares das proteínas, além de causarem associações proteína-proteína, o que produziu uma superfície compactada (Figura 3 E e F).

A concentração de ácidos urônicos em FAO e FAM antes da hidrólise $\left(17,1 \mathrm{mg} \mathrm{g}^{-1}\right)$, determinados na fração péctica por Seibel \& Beléia (2008), foi maior do que as relatadas por Bainy et al. (2008), que encontraram entre 8,18 a 14,01 $\mathrm{mg} \mathrm{g}^{-1}$ de ácidos urônicos em fibras obtidas de 12 variedades de soja. Huisman et al. (1998) comentaram que 90\% dos ácidos urônicos da farinha de soja estão na fração insolúvel, o que pode ser indicação da complexidade ou diversidade das moléculas pécticas na parede celular. A carboidrase foi capaz de solubilizar $73 \%$ dos carboidratos totais e $50 \%$ dos ácidos urônicos da quantidade inicial. Fischer et al. (2001) solubilizaram 76\% dos carboidratos de farinha de soja após tratamento enzimático e verificaram que a extração incompleta é decorrente da complexa estrutura dos compostos da soja. Marsman et al. (1997) solubilizaram praticamente a metade dos ácidos urônicos presentes em farinha de soja, quando utilizaram enzima para degradação de parede celular, mas isso ocorreu somente após 24 horas de hidrólise.

$\mathrm{O}$ efeito do $\mathrm{pH}$ na solubilidade das proteínas das fibras de soja e das frações sólidas resultantes da hidrólise com a carboidrase foi avaliado utilizando soluções com pH de 3 a 7 (Tabela 3). Para FAO e FAM, a quantidade de proteínas solúveis foi menor em $\mathrm{pH} 3$ (FAO 5,7\% e FAM 4,7\%), e máxima em pH 7 (FAO $7,6 \%$ e FAM 10,7\%), pois a proteína solúvel já havia sido extraída no processo industrial de produção de isolado proteico. As frações sólidas da hidrólise com carboidrases apresentaram maior solubilidade proteica, em todas as soluções avaliadas, quando comparadas às amostras não hidrolisadas ( $\mathrm{p}>0,05)$. A fração sólida do hidrolisado da FAO teve a solubilidade triplicada para $19,5 \%$ e o hidrolisado da FAM duplicou para $19,8 \%$. Essa diferença pode ser decorrente da micronização. As quantidades de proteínas solúveis passíveis de extração e aproveitamento nos pH 3, 5 e 6 das frações sólidas da FAO foram maiores do que as da FAM, provavelmente pelas diferenças nas conformações e agregações formadas pelas proteínas e também pelo tamanho e distribuição dos poros (Guillon \& Champ, 2000).

As frações sólidas da FAO e daFAM hidrolisadas com protease foram avaliadas quanto aos teores de proteínas e fibras alimentares e comparadas às amostras antes da hidrólise (Tabela 4). Em média, a protease foi capaz de solubilizar $54 \%$ do total das proteínas das amostras, e a quantidade de fibras alimentares totais aumentou de 60 para $76 \%$, com as fibras insolúveis sendo as frações majoritárias nas duas amostras, antes e depois da hidrólise. Essas frações sólidas das hidrólises podem ser utilizadas como ingredientes em vários produtos, pois o aumento da concentração de fibras totais permite o uso como ingrediente (fonte de fibras) em concentrações menores, em comparação com os ingredientes originais. Além disso, podem ter efeitos benéficos à saúde, com consumo diário total entre 25 e $30 \mathrm{~g}$, sendo $75 \%$ na forma insolúvel. Os benefícios descritos são: aumento da saciedade, regulação do trânsito intestinal, aumento do volume fecal (principalmente as insolúveis), redução do colesterol, aumento na excreção de sais biliares e prevenção de algumas doenças, incluindo o câncer de cólon (principalmente as solúveis) (Tharanathan \& Mahadevamma, 2003).

As frações solúveis da proteólise foram avaliadas quanto ao peso molecular dos peptídeos, juntamente com as proteínas solúveis das fibras alimentares não hidrolisadas e das proteínas solúveis das amostras tratadas com carboidrase (Figura 4). Para a eletroforese em gel, foram usados $2 \mathrm{mg}$ de proteínas solubilizadas em tampão (Tris-HCl, SDS, beta-mercaptoetanol e glicerol). Os sobrenadantes da hidrólise com a protease foram diluídos no tampão, enquanto as outras amostras foram extraídas nesse tampão. Para as duas amostras de fibras alimentares, a extração das proteínas no tampão foi total, mas parcial para as amostras de fibras hidrolisadas com carboidrase (60\% para a FAO e 50\% para a FAM).

Pesq. agropec. bras., Brasília, v.44, n.10, p.1336-1345, out. 2009 
A fração proteica, associada às fibras de cotilédones, FAO e FAM, é composta por proteínas majoritárias da soja, beta-conglicinina e glicinina, respectivamente, globulinas $7 \mathrm{~S}$ e $11 \mathrm{~S}$. As amostras apresentaram as
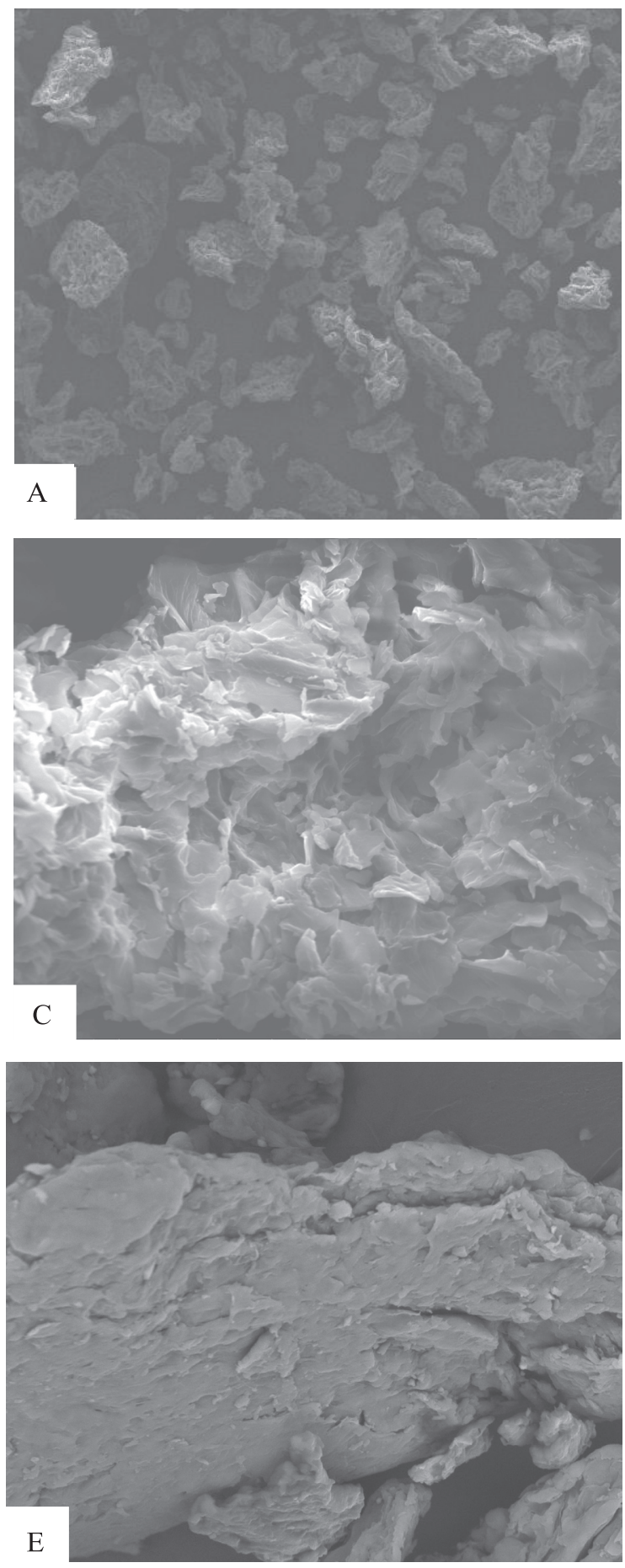

subunidades que constituem a beta-conglicinina, $\alpha$, $\alpha$ ' e $\beta$, com pesos moleculares de 84,72 e $51 \mathrm{KDa}$, respectivamente, e as subunidades ácidas (36-40 KDa) e básicas (18-20 KDa) que compõem a glicinina
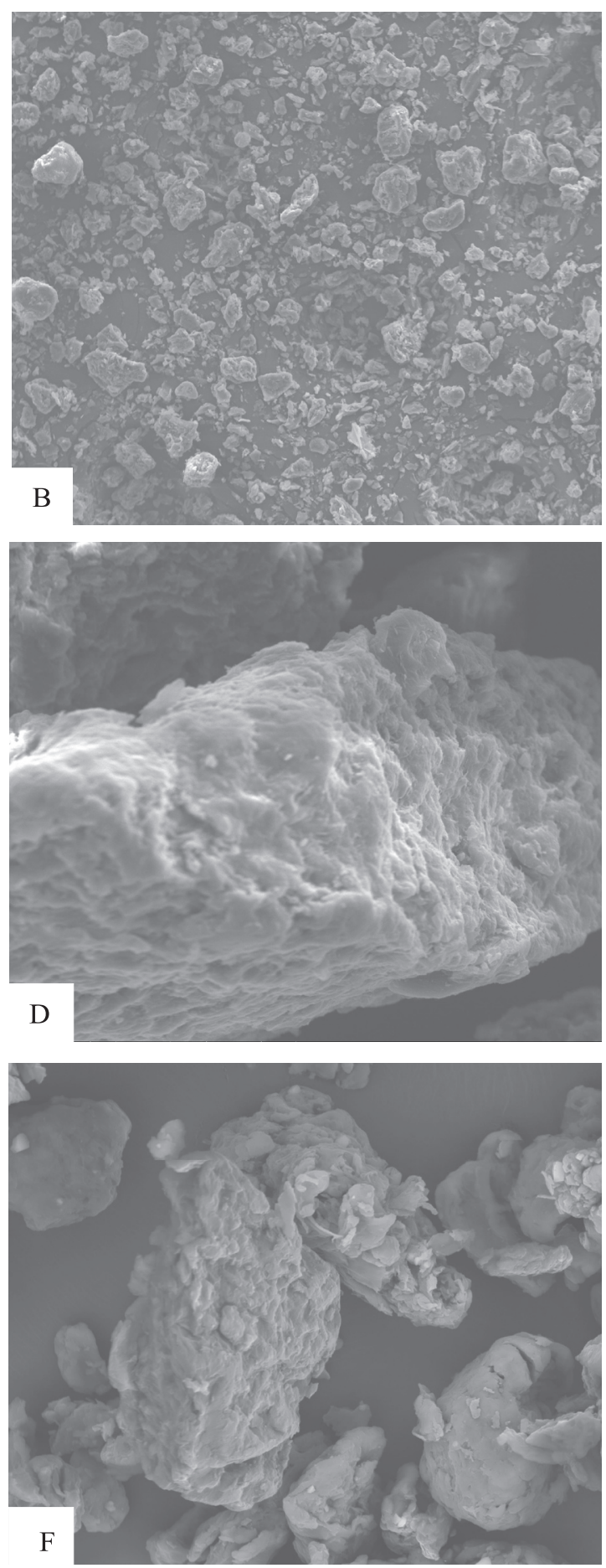

Figura 3. Microscopia eletrônica de varredura das fibras de soja sob a forma de fibra alimenar original (A), micronizada (B) (160x), original hidrolisada com protease (C), micronizada hidrolisada com protease (D), original hidrolisada com carboidrase (E) e micronizada hidrolisada com carboidrase (F) (800x). 
(Garcia et al., 1997; Riblett et al., 2001). Uma banda de menor intensidade foi verificada em $15 \mathrm{KDa}$, provavelmente uma subunidade da glicinina, o que também foi verificado por Riblett et al. (2001) que, ao avaliar as frações $7 \mathrm{~S}$ e 11S separadamente, observaram que essa banda foi revelada na eletroforese de glicinina, com baixa intensidade. De acordo com a análise visual da eletroforese, a protease hidrolisou as proteínas das fibras de soja a peptídeos com pesos moleculares menores que $10 \mathrm{KDa}$. Lee et al. (2001) comentaram que os hidrolisados de farinha de soja, oriundos da proteólise com várias proteases diferentes, inclusive a produzida pelo Bacillus licheniformis, resultaram em peptídeos com pesos moleculares menores que 12,5 KDa após 6 horas de hidrólise. O mesmo comportamento foi verificado quando a enzima utilizada foi a Viscozyme L (carboidrase). Isso provavelmente ocorreu porque essa enzima não é pura e contém alguma protease. Essa redução de peso molecular, pela carboidrase, também pode ter sido influenciada pelo tempo de hidrólise, 12 horas, mais do que duas vezes o da proteólise.

Bandas com peso molecular próximo aos $30 \mathrm{KDa}$ também foram reveladas na eletroforese das amostras de fibras de cotilédones, provavelmente glicoproteínas de parede celular ricas em hidroxiprolina. Segundo Kleis-San Francisco \& Tierney (1990), essas proteínas têm peso molecular que varia de 30 a $33 \mathrm{KDa}$ e tem a

Tabela 3. Efeito do $\mathrm{pH}$ na solubilidade proteica das frações sólidas das fibras dos cotilédones de soja após a hidrólise enzimática com a carboidrase, comparadas com as fibras não hidrolisadas $(\%$ de proteínas solúveis em relação às proteínas totais) $)^{(1)}$.

\begin{tabular}{lrrrrr}
\hline Amostras $^{(2)}$ & \multicolumn{5}{c}{$\mathrm{pH}$} \\
\cline { 2 - 6 } & \multicolumn{1}{c}{3} & \multicolumn{1}{c}{5} & \multicolumn{1}{c}{6} & \multicolumn{1}{c}{7} \\
\hline FAO não hidrolisada & $5,7 \pm 0,5 \mathrm{c}$ & $6,0 \pm 0,5 \mathrm{~b}$ & $6,7 \pm 0,1 \mathrm{~d}$ & $7,7 \pm 0,4 \mathrm{c}$ & $7,6 \pm 0,1 \mathrm{c}$ \\
FAO após a hidrólise & $13,5 \pm 0,3 \mathrm{a}$ & $15,2 \pm 1,8 \mathrm{a}$ & $18,6 \pm 0,4 \mathrm{a}$ & $20,8 \pm 0,3 \mathrm{a}$ & $19,5 \pm 0,6 \mathrm{a}$ \\
FAM não hidrolisada & $4,7 \pm 0,3 \mathrm{c}$ & $6,4 \pm 0,7 \mathrm{~b}$ & $9,6 \pm 0,3 \mathrm{c}$ & $10,5 \pm 0,3 \mathrm{c}$ & $10,7 \pm 0,3 \mathrm{~b}$ \\
FAM após a hidrólise & $10,4 \pm 0,4 \mathrm{~b}$ & $12,5 \pm 0,7 \mathrm{a}$ & $13,3 \pm 0,4 \mathrm{~b}$ & $16,4 \pm 2,2 \mathrm{~b}$ & $19,8 \pm 1,6 \mathrm{a}$ \\
\hline${ }^{(1)}$ Médias seguidas pela mesma letra, nas colunas, não diferiram pelo teste \\
de Tukey, a 5\% de probabilidade. Médias de determinações em triplicata, \\
em base seca. ${ }^{(2)}$ FAO, fibra alimentar original; FAM, fibra alimentar \\
micronizada.
\end{tabular}

mesma quantidade de hidroxiprolina e prolina. Quando as fibras foram hidrolisadas com protease por 5 horas (colunas 3 e 6 da Figura 4), apresentaram uma banda com peso molecular próximo aos $25 \mathrm{KDa}$, resultado da ação das enzimas, pois as amostras não hidrolisadas não contêm essa banda. Possivelmente, essa banda refere-se à glicoproteína de parede celular parcialmente hidrolisada, pois esses polipeptídeos são mais resistentes à hidrólise enzimática em razão da complexa estrutura e associação com outros compostos, que dificultam o acesso da enzima (Karr-Lilienthal et al., 2005). Marsman et al. (1997) recomendaram o uso de misturas de várias enzimas para degradação de compostos de parede celular, em menores concentrações, em vez de adicionar uma protease ou carboidrase separadamente, em maior concentração.

As análises por microscopia eletrônica de varredura das fibras de cotilédones de soja, FAO e FAM (Figura $3 \mathrm{~A}$ e B), representam a real estrutura física das amostras, pois a micronização foi realizada na empresa fornecedora do material. A redução, visível ao comparar as amostras na mesma magnificação, mostra que a fibra de cotilédones de soja micronizada é constituída, em maior proporção, de partículas menores em relação à fibra alimentar original. A diferença no tamanho das partículas justifica a maior densidade apresentada pela FAO $\left(0,46 \mathrm{~g} \mathrm{~mL}^{-1}\right)$, quando comparada à FAM $\left(0,39 \mathrm{~g} \mathrm{~mL}^{-1}\right)$, as quais apresentaram diferença estatística $(p>0,05)$. Esse comportamento foi observado por Cadden (1987) que, ao avaliar fibras de trigo e aveia, observou que o volume específico pode ser usado como um índice de diferença estrutural.

As microfotografias das amostras hidrolisadas com protease e com carboidrase não representam o tamanho real das partículas, pois o processo de secagem foi realizado com uma fina camada de amostra sobre uma superfície de vidro. O material seco formou uma cobertura compactada de fibras alimentares hidrolisadas, que foram moídas para proceder às análises microscópicas. A estrutura

Tabela 4. Caracterização das fibras de cotilédones de soja não hidrolisadas e das frações sólidas das fibras hidrolisadas com a protease $(\%)^{(1)}$.

\begin{tabular}{lccc}
\hline Amostras $^{(2)}$ & Proteínas & Fibras insolúveis & Fibras solúveis \\
\hline FAO não hidrolisada & $28,2 \pm 6,5 \mathrm{a}$ & $55,5 \pm 0,5 \mathrm{~b}$ & $3,8 \pm 0,1 \mathrm{c}$ \\
FAO após a hidrólise & $16,1 \pm 0,2 \mathrm{~b}$ & $70,6 \pm 1,2 \mathrm{a}$ & $4,4 \pm 0,6 \mathrm{bc}$ \\
FAM não hidrolisada & $27,6 \pm 0,1 \mathrm{a}$ & $56,6 \pm 0,4 \mathrm{~b}$ & $7,9 \pm 1,0 \mathrm{ab}$ \\
FAM após a hidrólise & $14,8 \pm 0,3 \mathrm{~b}$ & $72,4 \pm 1,8 \mathrm{a}$ & $62,5 \pm 0,8 \mathrm{a}$ \\
\hline
\end{tabular}

${ }^{(1)}$ Médias seguidas pela mesma letra, nas colunas, não diferem pelo teste de Tukey, a 5\% de probabilidade. Médias de determinações em triplicata, em base seca. ${ }^{(2)}$ FAO, fibra alimentar original. FAM, fibra alimentar micronizada. 


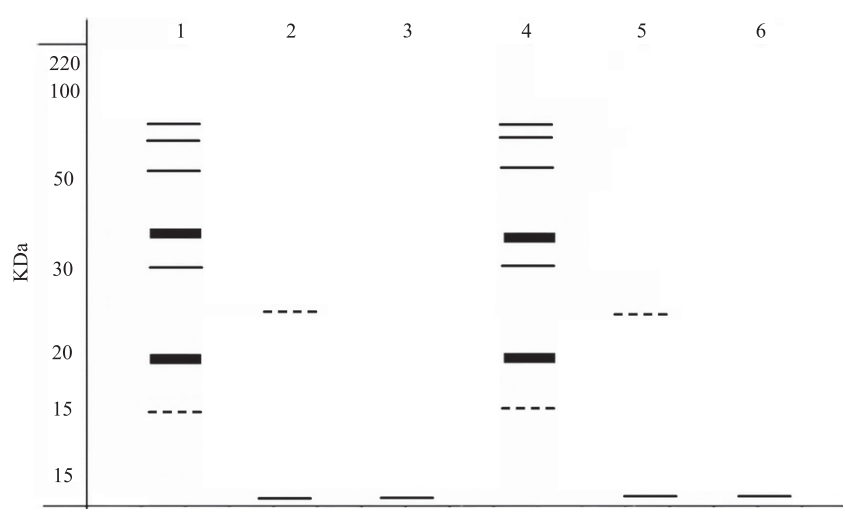

Figura 4. Zimograma da eletroforese de fibras de cotilédones de soja sob a forma de fibra alimentar original (FAO) e micronizada (FAM), e amostras hidrolisadas com protease e carboidrase, mostrando bandas fortes $(\square)$, médias $(-)$ e fracas (---). 1: FAO; 2: FAO hidrolisada com protease; 3: FAO hidrolisada com carboidrase; 4: FAM; 5: FAM hidrolisada com protease; 6: FAM hidrolisada com carboidrase.

física da amostra original hidrolisada com protease (Figura $3 \mathrm{C}$ ) ficou mais porosa superficialmente do que a fibra micronizada hidrolisada com a mesma enzima (Figura $3 \mathrm{D}$ ), provavelmente porque essa amostra não tinha sofrido modificações na estrutura antes da ação da enzima. A solubilização e a separação das proteínas deixaram as amostras menos compactadas do que a solubilização e a retirada dos carboidratos, pois as duas fibras alimentares hidrolisadas com carboidrase (Figuras 3 E e F), cuja fração sólida continha mais proteínas, apresentaram estrutura mais compacta. É possível que as proteínas, mais concentradas após a hidrólise dos carboidratos, tenham formado associações intermoleculares e intramoleculares, tendo mudado a agregação dessas macromoléculas, ou também tenham sido influenciadas pela temperatura usada na secagem.

\section{Conclusões}

1. As melhores condições de hidrólise das fibras de cotilédones de soja original e micronizada, para obter a maior solubilização de carboidratos e proteínas, são $200 \mu \mathrm{L} \mathrm{g}^{-1}$ durante 12 horas sob agitação a $30^{\circ} \mathrm{C}$, para a carboidrase, e $150 \mu \mathrm{L} \mathrm{g}^{-1}$ durante 5 horas sob agitação a $55^{\circ} \mathrm{C}$, para a protease.

2. $\mathrm{Na}$ fração sólida das fibras hidrolisadas com carboidrase, há concentração de proteínas de reserva da soja (beta-conglicinina e glicinina), com potencial para uso em alimentos, enquanto, nas frações solúveis, há maior quantidade de carboidratos e metade dos ácidos urônicos das amostras das fibras de cotilédones de soja original e micronizada inicialmente analisadas.

3. O tratamento com protease resulta em um material sólido com alta concentração de fibras alimentares (76\%), especialmente insolúveis, e a fração solúvel é constituída por proteínas de baixo peso molecular.

\section{Agradecimentos}

Ao Conselho Nacional de Desenvolvimento Científico e Tecnológico, pelo auxílio financeiro; ao Professor Fábio Yamashita, pelo auxílio no planejamento experimental; e à Solae Company, pelo fornecimento de amostras.

\section{Referências}

AOAC INTERNATIONAL. Official methods of analysis. 16.ed. Arlington: AOAC International, 1995. v.1-2.

AUFFRET, A.; RALET, M.C.; GUILLON, F.; BARRY, J.L.; THIBAULT, J.F. Effect of grinding and experimental conditions on the measurement of hydration properties of dietary fibers. Food Science and Technology, v.27, p.166-172, 1994.

BAINY, E.M.; TOSH, S.M.; CORREDIG, M.; POYSA, V.; WOODROW, L. Varietal differences of carbohydrates in defatted soybean flour and soy protein isolate by-products. Carbohydrate Polymers, v.72, p.664-672, 2008.

CADDEN, A.M. Comparative effects of particle size reduction on physical structure and water binding properties of several plant fibers. Journal of Food Science, v.52, p.1595-1599, 1987.

CHOU, D.H.; MORR, C.V. Protein-water interactions and functional properties. Journal of the American Oil Chemists Society, v.56, p.53-62, 1979.

DUBOIS, M.; GILLES, K.A.; HAMILTON, J.K.; REBERS, P.A.; SMITH, F. Colorimetric method for determination of sugars and related substances. Analytical Chemistry, v.28, p.350-356, 1956.

FISCHER, M.; KOFOD, L.V.; SCHOLS, H.A.; PIERSMA, S.R.; GRUPPEN, H.; VORAGEN, A.G.J. Enzymatic extractability of soybean meal proteins and carbohydrates: heat and humidity effects. Journal of Agricultural and Food Chemistry, v.49, p.4463-4469, 2001.

GARCIA, M.C.; TORRE, M.; MARINA, M.L.; LABORDA, F. Composition and characterization of soybean and related products. Critical Reviews in Food Science and Nutrition, v.37, p.361-391, 1997.

GUILLON, F.; CHAMP, M. Structural and physical properties of dietary fibers, and consequences of processing on human physiology. Food Research International, v.33, p.233-245, 2000.

HUISMAN, M.M.H.; SCHOLS, H.A.; VORAGEN, A.G.J. Cell wall polysaccharides from soybean (Glycine max) meal. Isolation and characterization. Carbohydrate Polymers, v.37, p.87-95, 1998. 
KARR-LILIENTHAL， L.K.; KADZERE, C.T.; GRIESHOP, C.M.; FAHEY JUNIOR, G.C. Chemical and nutritional properties of soybean carbohydrates as related to non ruminants: a review. Livestock Production Science, v.97, p.1-12, 2005.

KINTNER, P.K.; VAN BUREN, J.P. Carbohydrate interference and its correction in pectin analysis using the m-hydroxydiphenil method. Journal of Food Science, v.47, p.756-764, 1982.

KLEIS-SAN FRANCISCO, S.M.; TIERNEY, M.L. Isolation and characterization of a proline-rich cell wall protein from soybean seedlings. Plant Physiology, v.94, p.1897-1902, 1990.

LAHL, W.J.; BRAUN, S.D. Enzymatic production of protein hydrolysates for food use. Food Technology, v.48, p.68-71, 1994.

LEE, J.Y.; LEE, H.D.; LEE, C.H. Characterization of hydrolysates produced by mild-acid treatment and enzymatic hydrolysis of defatted soybean flour. Food Research International, v.34, p.217-222, 2001.

LÓPEZ, G.; ROS, G.; RINCON, F.; PERIAGO, M.J.; MARTÍNEZ, M.C.; ORTUÑO, J. Relationship between physical and hydration properties of soluble and insoluble fiber of artichoke. Journal of Agricultural and Food Chemistry, v.44, p.2773-2778, 1996.

LOWRY, O.H.; ROSEBROUGH, N.J.; FARR, A.L.; RANDALL, R.J. Protein measurement with the folin phenol reagent. Journal Biological Chemistry, v.193, p.265-275, 1951.

MARSMAN, G.J.P.; GRUPPEN, H.; MUL, A.J.; VORAGEN, A.G.J. In vitro accessibility of untreated, toasted, and extruded soybean meals for proteases and carbohydrases. Journal of Agricultural and Food Chemistry, v.45, p.4088-4095, 1997.

MARUYAMA, N.; FUKUDA, T.; SAKA, S.; INUI, N.; KOTOH, J.; MIYAGAWA, M.; HAYASHI, M.; SAWADA, M.; MORIYAMA, T.; UTSUMI, S. Molecular and structural analysis of electrophoretic variants of soybean seed storage proteins. Phytochemistry, v.64, p.701-708, 2003.
PADILLA, F.C.; ALVAREZ, M.T.; ALFARO, M.J. Functional properties of barinas nut flour (Caryodendron orinocense Karst., Euphorbiaceae) compared to those of soybean. Food Chemistry, v.57, p.191-196, 1996.

RIBLETT, A.L.; HERALD, T.J.; SCHMIDT, K.A.; TILLEY, K.A. Characterization of $\beta$-conglycinin and glycinin soy protein fractions from four selected soybean genotypes. Journal of Agricultural and Food Chemistry, v.49, p.4983-4989, 2001.

SEIBEL, N.F. Caracterização, fracionamento e hidrólise enzimática dos componentes do resíduo do processamento da soja (Glycine max (L.) Merrill), fibras dos cotilédones. 2006. 103p. Tese. (Doutorado) - Universidade Estadual de Londrina, Londrina.

SEIBEL, N.F.; BELÉIA, A. del P. Carboidratos das fibras de cotilédones e proteínas de produtos derivados de soja (Glycine max (L.) Merril). Ciência e Tecnologia de Alimentos, v.28, p.607-613, 2008.

SGARBIERI, V.C. Propriedades funcionais de proteínas em alimentos. Boletim da Sociedade Brasileira de Ciência e Tecnologia de Alimentos, v.32, p.105-126, 1998.

THARANATHAN, R.N.; MAHADEVAMMA, S. Grain legumes a boon to human nutrition. Trends in Food Science \& Technology, v.14, p.507-518, 2003.

THIBAULT, J.F.; LAHAYE, M.; GUILLON, F. Physico-chemical properties of food plant cell wall. In: SCHEIZER, T.F.; EDWARDS, C.A. Dietary fiber: a component of food: nutritional function in health and disease. Berlin: Springer-Verlag, 1992. p.21-39.

TSUMURA, K.; SAITO, T.; TSUGE, K.; ASHIDA, H.; KUGIMIYA, W.; INOUYE, K. Functional properties of soy protein hydrolysates obtained by selective proteolysis. Food Science and Technology, v.38, p.255-261, 2005.

$\overline{\text { Recebido em } 26 \text { de janeiro de } 2009 \text { e aprovado em } 30 \text { de setembro de } 2009}$ 